\title{
A Prospective Study of Inpatient Ketamine Subanaesthetic Dose Infusion in Chronic Refractory Pain
}

\author{
Teik Guan Tay ${ }^{1}$, Tony Hollins ${ }^{1}$, Ben Teoㄹ, Kok Eng Khor ${ }^{1,2}$, James Tekiko1 \\ ${ }^{1}$ Department of Pain Management, Prince of Wales Hospital, Sydney, Australia \\ ${ }^{2}$ Prince of Wales Clinical School, University of New South Wales, Sydney, Australia \\ Email: teiktay2010@gmail.com, tony.hollins@health.nsw.gov.au, ben.teo@health.nsw.gov.au, \\ kokeng.khor@health.nsw.gov.au, james.tekiko@health.nsw.gov.au
}

How to cite this paper: Tay, T.G., Hollins, T., Teo, B., Khor, K.E. and Tekiko, J. (2021) A Prospective Study of Inpatient Ketamine Subanaesthetic Dose Infusion in Chronic Refractory Pain. Pain Studies and Treatment, 9, 17-35.

https://doi.org/10.4236/pst.2021.93003

Received: June 6, 2021

Accepted: July 10, 2021

Published: July 13, 2021

Copyright $\odot 2021$ by author(s) and Scientific Research Publishing Inc. This work is licensed under the Creative Commons Attribution International License (CC BY 4.0).

http://creativecommons.org/licenses/by/4.0/

\begin{abstract}
Background: Inpatient subanaesthetic ketamine infusion for 5 days may improve pain and reduce oral opioid usage in patients with chronic pain. Objective: This study aims to investigate pain and psychological outcomes of ketamine parenteral infusion $(0.1-0.35 \mathrm{mg} / \mathrm{kg} / \mathrm{h}$ or maximum $24 \mathrm{mg} / \mathrm{hour})$ for 5 days in patients with chronic refractory pain. The secondary objective is to explore any prognostic pain and psychological factors associated with the successful response to the ketamine treatment. Methodology: A prospective longitudinal study of a small cohort $(\mathrm{N}=35)$ of patients with heterogenous chronic refractory pain conditions was conducted from one week to two months follow-up. Results: Pain Severity was significantly improved from mean 6.5 to $5.1(\mathrm{t}=3.77, \mathrm{p}<0.001, \mathrm{~d}=0.6)$ at 1 -week and $5.9(\mathrm{t}=2.14, \mathrm{p}=$ $0.042, \mathrm{~d}=0.4)$ at 2-month; Pain Interference from mean 7.0 to $5.1(\mathrm{t}=4.99$, $\mathrm{p}<0.001, \mathrm{~d}=0.9)$ at 1 -week and $6.1(\mathrm{t}=2.16, \mathrm{p}=0.041, \mathrm{~d}=0.4)$ at 2-month; Pain Self-Efficacy Questionnaire (PSEQ) from mean 17 to $24(\mathrm{t}=-3.37, \mathrm{p}=$ $0.002, \mathrm{~d}=-0.6)$ at 1 -week and $23(\mathrm{t}=-2.60, \mathrm{p}=0.016, \mathrm{~d}=-0.5)$ at 2 -month; Pain Catastrophizing (PCS) from 28 to $23(\mathrm{t}=3.4, \mathrm{p}=0.002 ; \mathrm{d}=0.6)$ at 1-week and $21(\mathrm{t}=2.45, \mathrm{p}=0.022, \mathrm{~d}=0.5)$ at 2-month; Depression from mean 21 to $16(\mathrm{t}=2.16, \mathrm{p}=0.038, \mathrm{~d}=0.4)$ at 1 -week and $16(\mathrm{t}=3.53, \mathrm{p}=$ $0.002, \mathrm{~d}=0.7)$ at 2 -month; and oral Morphine Equivalent Daily Dose (oMEDD) reduced from mean $191 \mathrm{mg} /$ day on admission to $122 \mathrm{mg} /$ day at 1-week $(\mathrm{t}=2.38, \mathrm{p}=0.023 ; \mathrm{d}=0.4)$ and $93 \mathrm{mg} /$ day at 2 -month $(\mathrm{t}=2.59, \mathrm{p}=$ $0.016 ; d=0.5)$. There was no significant difference between responders and non-responders on baseline psychological measures $\left(t_{33}<1.19, p>0.244\right)$ and pain classifications $\left(\chi_{3}^{2}=0.610, p=0.894\right)$. Conclusion: Ketamine subanaesthetic dose infusion for 5 days was found to be effective in managing
\end{abstract}


chronic refractory pain with significant opioid reduction and small improvements in all chronic pain outcomes, except anxiety, at 1-week and 2-month follow-up and with minimal severe adverse effects.

\section{Keywords}

Chronic Refractory Pain, Ketamine Infusion, Chronic Refractory Pain Treatment, Ketamine Therapy, Pharmacotherapy

\section{Introduction}

The short-term analgesic and rapid anti-depressant effects of subanaesthetic ketamine infusion in chronic refractory pain have been widely reported in the literature [1] [2] [3] [4]. Current literature suggests that if used cautiously, ketamine infusion is safe, modestly effective, well-tolerated and can be used to treat opioid-induced tolerance or hyperalgesia in patients with chronic refractory pain [5] [6] [7] [8]. Expert consensus guidelines support the use of ketamine for chronic refractory pain but the level of evidence varies according to dose range, route of delivery and pain conditions [5].

Ketamine is efficacious in a variety of chronic pain conditions such as Complex Regional Pain Syndrome (CRPS) [9] [10], spinal cord injury pain [11], fibromyalgia [12], peripheral neuropathic pain [13] [14], phantom limb pain [15], postherpetic neuralgia [16] and opioid-induced hyperalgesia [17] [18]. Recent evidence from systematic reviews and meta-analysis of randomized controlled trials by Jasper [18], Orhurhu [19] and Michelet [20] confirmed subanaesthetic ketamine infusion provided a short-term analgesic response from 2 weeks [19] to 12 weeks [20] in chronic refractory pain. In contrast, controlled studies of multiday low dose ketamine infusion in patients with CRPS reported a long-term analgesic response of 3 months [9] [10] [21] and up to 3 years in a retrospective case series [22]. Long-term responses to ketamine were dose-related, with cumulative effects in repeated and multiday ketamine infusions were postulated to be dose-related [9] [10] [21] [22]. The reviewers hypothesize that active metabolites of ketamine (e.g. nor-ketamine) may play an important role in enduring effects on chronic pain through its neuromodulatory effects on the affective and motivational dimensions of chronic pain [23]. Ketamine may have novel applications as an adjuvant pharmacotherapy to facilitate psycho-behavioural modification in chronic pain, depression and substance use disorder.

Recently, there is evidence showing that intravenous ketamine infusion provides rapid antidepressant and anti-suicidal responses in patients with Treatment Resistant Depression (TRD) [24] [25] and in war veterans with chronic pain [26]. However, there are concerns for recreational misuse, tachyphylaxis, bladder toxicity and hepatotoxicity if ketamine is misused or abused long term 


\section{[27] [28] [29].}

We postulate that chronic refractory pain is a complex pain condition predominantly mediated by central sensitization caused by excessive NMDA receptor activation resulting in cellular and subcellular changes in the central nervous system. Furthermore, researchers have shown that individual perception and/or experience of chronic pain may be influenced by psychosocial factors, such as self-efficacy, depression, anxiety, stress and catastrophizing. The amount of opioid use in a chronic pain patient may also reflect a patient's lack of pain coping skills, high levels of psychosocial stress, and/or deficiency in descending noxious inhibitory pathways. The primary objective of this study was to investigate the immediate (1-week) and longer term (2-month) responses of pain severity and pain interference after a subanaesthetic dose of ketamine infusion (0.1 - $0.35 \mathrm{mg} / \mathrm{kg} / \mathrm{h}$ or maximum $24 \mathrm{mg} / \mathrm{hour}$ ) for 5 days as an inpatient treatment for chronic refractory pain. Our secondary objectives were to assess the change in oral Morphine Equivalent Daily Dose (oMEDD) and other psychological outcome measures (pain self-efficacy, depression, anxiety, stress and pain catastrophizing) following ketamine infusion. The final objective was to investigate any baseline predictive factors (e.g. pain phenotype classifications, pain severity \& interference, oMEDD usage, psychological outcome measures) that may differ between responders and non-responders to ketamine infusion.

\section{Methodology}

\subsection{Study Design}

This is a prospective open label longitudinal observational study of a cohort of inpatients with heterogenous refractory chronic pain conditions admitted for 5 days of subanaesthetic ketamine infusion $(0.1-0.35 \mathrm{mg} / \mathrm{kg} /$ hour, maximum 24 $\mathrm{mg} / \mathrm{h}$ ). Baseline data were collected before commencement of the infusion and the outcome measures collected at 1 week (at the end of infusion) and at 2 months follow-up. The study was approved by the Local Ethics Committee of the South Eastern Sydney Local Health District (HREC reference no. 14/136 (LNR/14/POWH/692).

\subsection{Patient Selection Process}

Patients with chronic refractory pain syndromes of heterogenous phenotypes referred to the Pain Management Clinic at the Prince of Wales Hospital having undergone multidisciplinary assessment who were offered an inpatient ketamine infusion treatment as part of management were invited to participate in the study from 2014 to 2019. Informed consent was obtained from all participants prior to the study commencement by the patient's attending pain physician. This included discussions of the risks and benefits of the ketamine infusion. Participants were generally offered a planned 5-day of inpatient admission for the ketamine infusion and all data related to the study were collected by the pain nurse involved in the study. 
Inclusion criteria:

1) Patients able to provide written informed consent prior to the enrolment.

2) Patients diagnosed with severe debilitating chronic refractory ( $>3$ months) pain unresponsive to conventional multimodal medical therapy or multidisciplinary management.

3) Patients with no contraindications or known allergy to ketamine.

4) Patient with heterogenous chronic primary and secondary pain disorders as described in IASP (International Association of Study of Pain).

5) Patient with severe chronic pain disorder that severely interfered with daily activities and psychological well-being (e.g. depression, anxiety and drug dependency).

Exclusion criteria:

1) Patients with unstable psychological or psychiatric conditions, e.g. untreated bipolar disorder, post-traumatic stress disorder, major depression with acute suicidality, severe personality disorder and psychotic illness.

2) Patients having recently undergone major interventional pain procedures, such as nerve blocks or implantable therapies within 3 months of enrolment.

3) Patients with ongoing litigation or legal proceedings with respect to their pain condition.

4) Patients with known drug dependency or substance use disorder specifically related to ketamine or other psycho-stimulant drugs.

5) Patient with previous severe reactions or allergy to ketamine.

6) Patient with severe cardiovascular, respiratory, hepatic, renal or other organ impairments.

\subsection{Ketamine Parenteral Infusion Protocol}

Ketamine was administered parenterally either by subcutaneous or intravenous infusion for 5 days, starting at a dose of $0.1-0.2 \mathrm{mg} / \mathrm{kg} / \mathrm{hour}$ according to patient body weight, age and general medical condition and increased gradually by $0.1-0.2 \mathrm{mg} / \mathrm{kg} /$ day slowly daily until significant pain relief was achieved, or development of intolerable adverse effects or a maximum dose of $0.35 \mathrm{mg} / \mathrm{kg} / \mathrm{hour}$ (or $24 \mathrm{mg} /$ day) was reached.

During the course of inpatient ketamine infusion treatment, the pharmacological interventions were limited to change of opioids or dose (e.g. opioid rotation, opioid reduction) and titration of other non-opioid pain medications in order to optimize pain relief and reduction of medication related harms.

This dose range of ketamine is unlikely to cause any potential serious complications. Transient minor side effects may occur, such as dizziness, nausea, hallucination, visual disturbance, tachycardia and hypertension. These transient adverse effects usually subside with the cessation of the ketamine infusion. The duration of ketamine infusion was limited to 5 days in order to allow for therapeutic response while avoiding long-term neurocognitive, hepatic and urological adverse effects. 


\subsection{Outcome Measures}

Baseline data collected included patient demographics, Body Mass Index (BMI), nicotine or alcohol use, pain phenotypes/classifications, number and location of pain, pain duration and pre-ketamine interventions e.g. nerve blocks and analgesic/opioid medications.

The multidimensional nature of chronic pain was assessed using the Brief Pain Inventory (BPI-SF) with subscales Pain Severity (BPI-PS) and Pain Interference (BPI-PI), the Pain Self-Efficacy Questionnaire (PSEQ), the Depression, Anxiety and Stress Scale (DASS-21) and the Pain Catastrophizing Scale (PCS). They were also used to measure the five clinical domains of chronic pain outcomes as recommended by Initiative on Methods, Measurement, and Pain Assessment in Clinical Trials (IMMPACT) [30], such as pain, physical functioning, psychological state, global impression of change, and adverse effects/complications of the clinical intervention. Catastrophization as part of chronic pain cognitions and coping strategies was measured using the Pain Catastrophizing Scale (PCS).

The patient's daily intake of opioids was also recorded and converted into the mean oral Morphine Equivalent Daily Dose (oMEDD) using the opioid conversion table published by the Faculty of Pain Medicine, Australian and New Zealand College of Anaesthetists (ANZCA) [31]. Adverse Effects and Complications (AEC) were monitored daily, documented and graded using the Likert Scale: 1) No adverse effects; 2) Mild adverse effects; 3) Moderate adverse effects; 4) Severe adverse effects; 5) Extremely severe adverse effects. The patient's perception of improvement with the ketamine infusion was measured at 1-week on discharge only using the two-item Global Perception of Improvement (GPI) questionnaire. Item 1 asked patients to rate the change in their Overall Status on a 7-point scale from -3 "Very much worse" to +3 "Very much improved". Item 2 asked patients to rate how much Pain Relief has been provided from " $0 \%$ No relief" to " $100 \%$ Complete relief". A successful response to the infusion was defined as a reported Pain Relief of $30 \%$ or more [33].

All outcome data (BPI, PSEQ, DASS-21, PCS, GPI, AEC, oMEDD) were collected at 1 week and recollected at 2 months after the ketamine infusion by the pain nurse who served as an independent observer. All data collected were entered into the Australasian online electronic Persistent Pain Outcome Collaboration (ePPOC) database. The data was then retrieved by the study investigators through an online login to the ePPOC system identifying the patient file, outcome data and date of service. At the end of the study, participants who withdrew from the study and their reasons were documented. Other relevant medical information including medications and doses were extracted from patient's medical records.

\subsection{Statistical Analysis}

Statistical analysis was conducting using the open source software tool Jamovi, developed by the University of Newcastle. The Student's paired samples t-test 
was used to detect differences in outcome measures between admission and discharge and between admission and follow-up. The Student's independent samples t-test was used to detect differences between males and females on admission and on discharge, between responders and non-responders on admission and at discharge, and between those who completed the outcome measures at follow-up and those who did not. Pearson's Chi-squared test was used to detect whether females and males were equally represented in the responder category. Significance level for all tests was set at $\mathrm{p}=0.05$.

\section{Results}

A total of 35 patients $(\mathrm{F}=19, \mathrm{M}=16)$ consented to participate in the study. The descriptive statistics on admission are shown in Table 1 . The participants' age ranged from 21 to 91 years (Mean 54.1, SD 15.5), mean BMI was $29.4 \mathrm{~kg} / \mathrm{m}^{2}$ (SD 7.3) and they were taking a mean oral morphine equivalent daily dose (oMEDD) of $191 \mathrm{mg} /$ day (SD 185).

Table 1. Baseline descriptive statistics on admission $(\mathrm{N}=35)$.

\begin{tabular}{|c|c|c|c|}
\hline & $\mathrm{N}$ & Mean & SD \\
\hline Sex & $\mathrm{F}=19 \mathrm{M}=16$ & & \\
\hline Age & 35 & 54.1 & 15.5 \\
\hline BMI & 34 & 29.4 & 7.3 \\
\hline Chronic Pain Classifications & 35 & & \\
\hline 1) Nociplastic & 13 & & \\
\hline 2) Neuropathic & 11 & & \\
\hline 3) Nociceptive & 7 & & \\
\hline 4) Mixed & 4 & & \\
\hline oMEDD (0 - 960) & 35 & 191.0 & 185.0 \\
\hline Pain Severity $(0-10)$ & 35 & 6.5 & 1.7 \\
\hline Pain Interference $(0-10)$ & 35 & 7.0 & 1.9 \\
\hline Depression $(0-42)$ & 35 & 21.3 & 12.6 \\
\hline Anxiety $(0-42)$ & 35 & 15.4 & 13.1 \\
\hline Stress $(0-42)$ & 35 & 21.1 & 12.0 \\
\hline PSEQ $(0-60)$ & 35 & 16.7 & 12.8 \\
\hline PCS $(0-52)$ & 35 & 28.4 & 12.6 \\
\hline
\end{tabular}

BMI: Body Mass Index in $\mathrm{kg} / \mathrm{m}^{2}$; Pain Classifications-Nociplastic (complex regional pain syndrome, fibromyalgia), neuropathic (nerve lesion or disease, peripheral or central), nociceptive (visceral organ pain, musculoskeletal-nonspecific low back pain), mixed (neuropathic and nociceptive pain, e.g. nonspecific low back pain with radiculaopathic pain); oMEDD: oral Morphine Equivalent Daily Dose in mg; Pain Severity and Pain Interference are subscales of the Brief Pain Inventory (BPI); Depression, Anxiety and Stress are subscales of the DASS-21; PSEQ: Pain Self-Efficacy Questionnaire; PCS: Pain Catastrophizing Scale; Socio-economic status-all patients are admitted under public health system, on disability sickness pension, unemployment benefits or retirement pension. 
Patients were classified according to the type of pain they described (Figure 1). The largest group was nociplastic pain $(\mathrm{N}=13)$ including Complex Regional Pain Syndrome (CRPS) and Fibromyalgia Syndrome (FMS). Another large group was neuropathic pain $(\mathrm{N}=11)$ including peripheral and central neuropathic pain. (e.g. radiculopathy and spinal cord injury pain). The smaller groups were nociceptive pain $(\mathrm{N}=4)$ including visceral pain and musculoskeletal pain, and lastly mixed pain $(\mathrm{N}=7)$ including mixed neuropathic and nociceptive pain as shown in Figure 1.

The outcome measures on admission and at 1-week were completed by all 35 patients. Due to incomplete data, only 25 patients (completers) were included in the analysis at the 2-month follow-up. There were no differences between completers and non-completers on any outcomes on admission $\left(t_{33}<1.67, p\right\rangle$ $0.105)$. At 1-week on discharge, oMEDD was found to be lower for completers (mean $96 \mathrm{mg}$ SD 81) compared to non-completers (mean $188 \mathrm{mg}$ SD 134) $\left(t_{33}=\right.$ 2.504, $p=0.017$ ). There were no differences between females and males on any outcome measures on admission or after 1-week on discharge $\left(t_{33}<1.52, p>\right.$ $0.138)$.

The results of statistical analysis of all pain and other outcome measures on admission, at 1-week on discharge and at 2-month follow-up are shown in Table 2.

1) Primary Pain Outcomes: Pain Severity (BPI-PS) and Pain Interference (BPI-PI)

Compared to admission, there were significant improvements in the BPI-Pain Severity scores at 1-week $(\mathrm{t}=3.77, \mathrm{p}<0.001, \mathrm{~d}=0.6)$ and at 2-month follow-up $(t=2.14, p=0.042, d=0.4)$, as shown in Figure 2. There were also significant improvements in the BPI-Pain Interference scores at 1 -week $(t=4.99, \mathrm{p}<0.001$, $\mathrm{d}-0.9)$ and at 2-month follow-up $(\mathrm{t}=2.16, \mathrm{p}=0.041, \mathrm{~d}=0.4)$, as shown in Figure 3.

2) Secondary Pain Related Outcomes: oMEDD, PSEQ, DASS and PCS

\section{Chronic Refractory Pain Classifications}

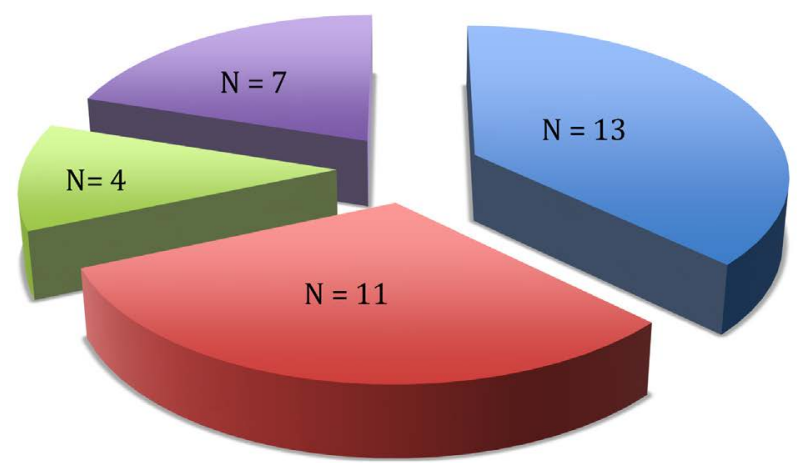

Nociplastic Pain (e.g. CRPS, FMS

Neuropathic Pain (e.g $\mathrm{SCI}$, radicular)

- Nociceptive Pain (e.g. Visceral, MSK)

aixed Pain

Figure 1. Chronic pain classification. CRPS: complex regional pain syndrome; FMS: fibromyalgia syndrome; SCI: spinal cord injury, MSK: musculoskeletal. 


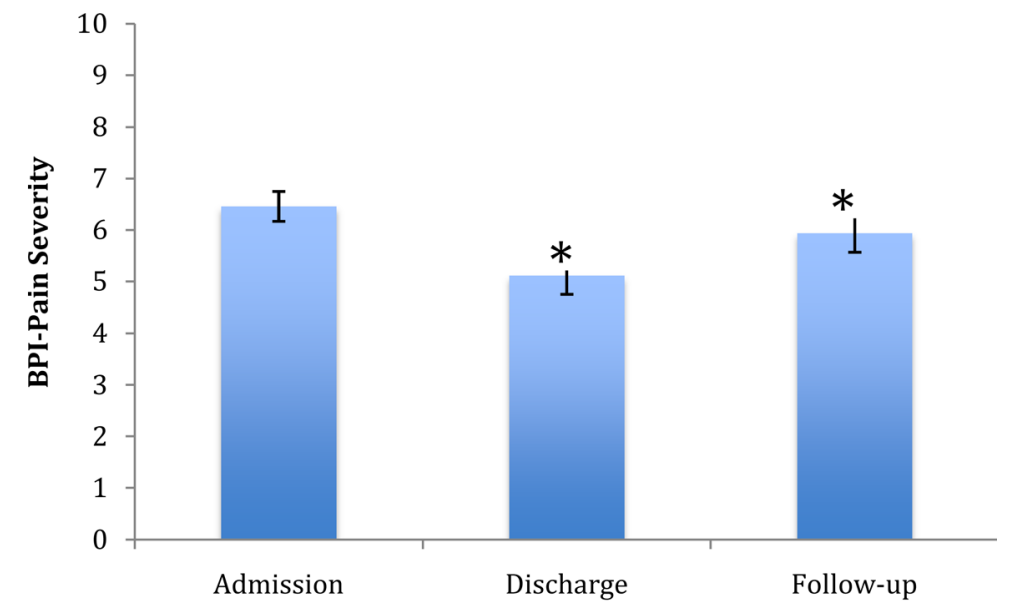

Figure 2. Brief Pain Inventory (BPI)-Pain Severity, Discharge, 1-week, Follow-up, 2-month, ${ }^{*} \mathrm{p}<0.05$.

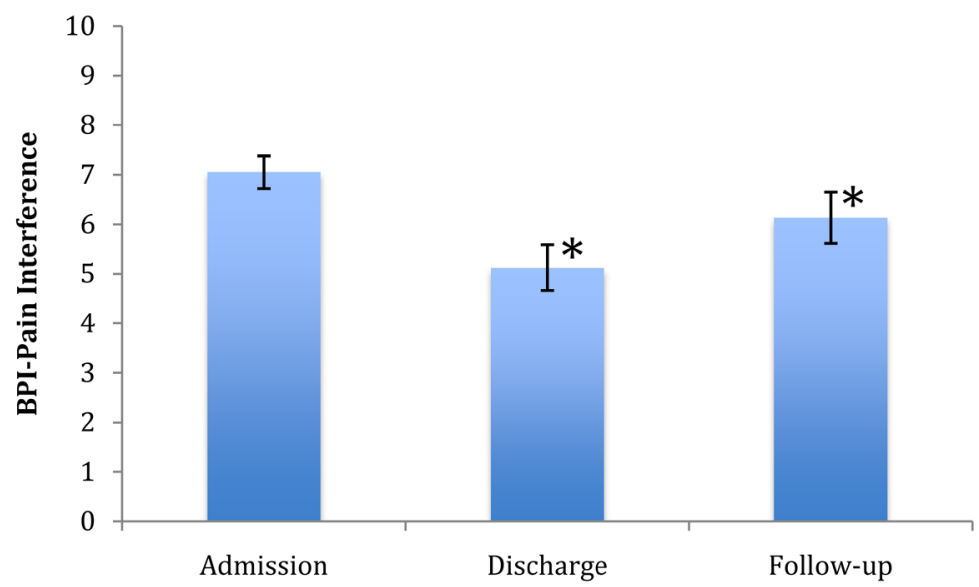

Figure 3. Brief Pain Inventory (BPI)-Pain Interference, Discharge, 1-week, Follow-up, 2-month, ${ }^{*} \mathrm{p}<0.05$.

Table 2. Comparison of outcomes of ketamine infusion from admission to 1-week discharge and 2-month follow-up.

\begin{tabular}{|c|c|c|c|c|c|c|c|c|c|}
\hline Time of Measurement & Admission & Discharge & Follow-up & \multicolumn{3}{|c|}{ Admission v Discharge } & \multicolumn{3}{|c|}{ Admission v Follow-up } \\
\hline \multirow[t]{2}{*}{ Number of Completers } & $\mathrm{N}=35$ & $\mathrm{~N}=35$ & $\mathrm{~N}=25$ & & $\mathrm{~N}=35$ & & & $\mathrm{~N}=25$ & \\
\hline & & Mean (SD) & & $t$ & $p$ & $d$ & $t$ & $p$ & $d$ \\
\hline oMEDD $(0-960)$ & $191(185)$ & $122(106)$ & $93(77)$ & 2.38 & $0.023^{\star}$ & 0.4 & 2.59 & $0.016^{*}$ & 0.5 \\
\hline Pain Severity $(0-10)$ & $6.5(1.7)$ & $5.1(2.2)$ & $5.9(1.8)$ & 3.77 & $<0.001^{*}$ & 0.6 & 2.14 & $0.042^{*}$ & 0.4 \\
\hline Pain Interference $(0-10)$ & $7.0(1.9)$ & $5.1(2.7)$ & $6.1(2.6)$ & 4.99 & $<0.001^{*}$ & 0.9 & 2.16 & $0.041^{\star}$ & 0.4 \\
\hline Depression $(0-42)$ & $21(13)$ & $16(15)$ & $16(13)$ & 2.16 & $0.038^{*}$ & 0.4 & 3.53 & $0.002^{*}$ & 0.7 \\
\hline Anxiety $(0-42)$ & $15(13)$ & $13(12)$ & $13(12)$ & 1.48 & 0.148 & 0.3 & 0.48 & 0.634 & 0.1 \\
\hline Stress $(0-42)$ & $21(12)$ & $16(13)$ & $17(13)$ & 3.06 & $0.004^{*}$ & 0.5 & 2.06 & $0.050^{*}$ & 0.4 \\
\hline Pain Self-Efficacy (0 - 60)@ & $17(13)$ & $24(15)$ & $23(15)$ & -3.37 & $0.002^{\star}$ & -0.6 & -2.60 & $0.016^{*}$ & -0.5 \\
\hline Pain Catastrophizing $(0-52)$ & $28(13)$ & $23(15)$ & $21(15)$ & 3.40 & $0.002^{*}$ & 0.6 & 2.45 & $0.022^{*}$ & 0.5 \\
\hline
\end{tabular}

Note. $\mathrm{H}_{\mathrm{a}}$ Measure $1 \neq$ Measure 2, $t=$ Student's $\mathrm{t}$ Test, $d=$ Cohen's $d$, oMEDD = oral Morphine Equivalent Daily Dose in mg/day. ${ }^{*} \mathrm{p} \leq 0.05, @$ Pain Self-Efficacy larger score is an improvement, Depression, Anxiety and Stress are subscales of the DASS-21. 
The following secondary outcomes were all significantly improved at both 1-week on discharge and at 2-month follow-up: oral Morphine Equivalent Daily Dose (oMEDD) is shown in Figure 4; Pain Self-Efficacy (PSEQ) in Figure 5; Depression and Stress in Figure 6 and Figure 7; and Pain Catastrophization Score (PCS) in Figure 8. There was no improvement in Anxiety at any time point.

The opioid oMEDD reduction was significant at 1 week from mean dose 191 $\mathrm{mg} /$ day (SD $185 \mathrm{mg}$ day) to $122 \mathrm{mg} /$ day (SD $106 \mathrm{mg} /$ day); and to $93 \mathrm{mg} /$ day (SD $77 \mathrm{mg} /$ day) at 2-month. The total mean oMEDD reduction of $191 \mathrm{mg} /$ day to 93 $\mathrm{mg} /$ day was $36 \%$ at 1 -week $(\mathrm{p}=0.023)$ and $122 \mathrm{mg} /$ day to $93 \mathrm{mg} /$ day was $51 \%$ at 2-month $(\mathrm{p}=0.016)$.

3) Responder Analysis ( $\geq 30 \%$ Pain Severity Reduction)

The Global Perception of Improvement (GPI) items of Overall Status and Pain Relief were completed by 26 patients at 1-week on discharge, with 9 patients not

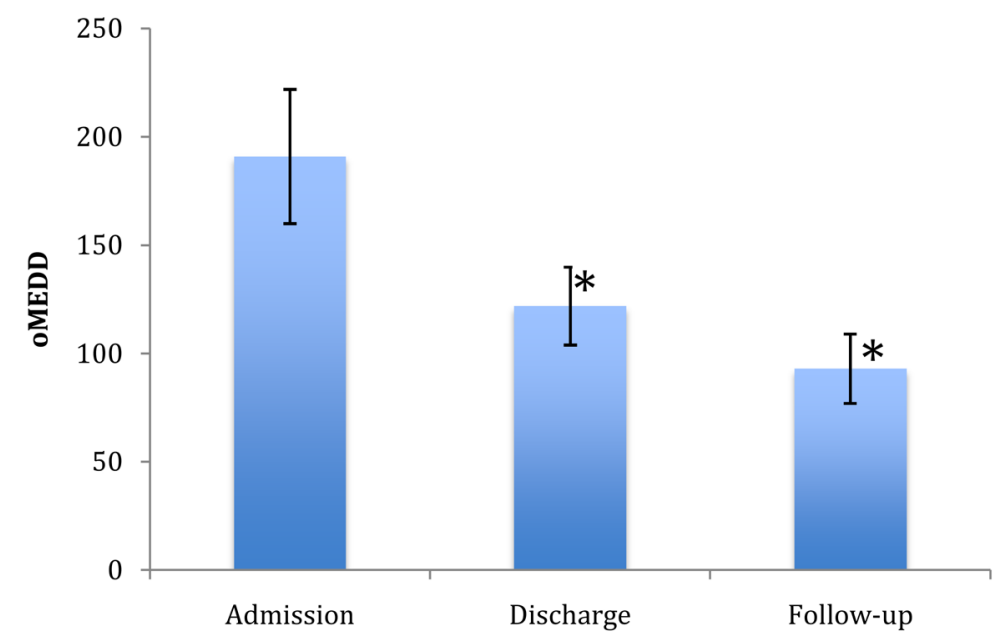

Figure 4. Oral Morphine Equivalent Daily Dose (oMEDD) mg/day, Discharge, 1-week, Follow-up, 2-month, ${ }^{*} \mathrm{p}<0.05$.

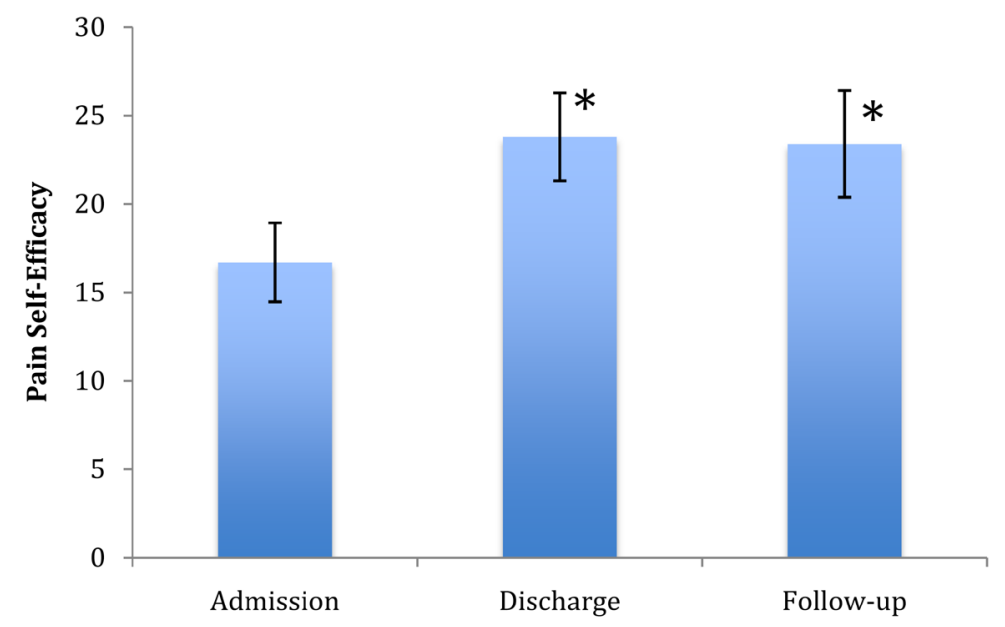

Figure 5. Pain Self-Efficacy (PSEQ) (0-60), Discharge, 1-week, Follow-up, 2-month, ${ }^{*} \mathrm{p}<0.05$. 


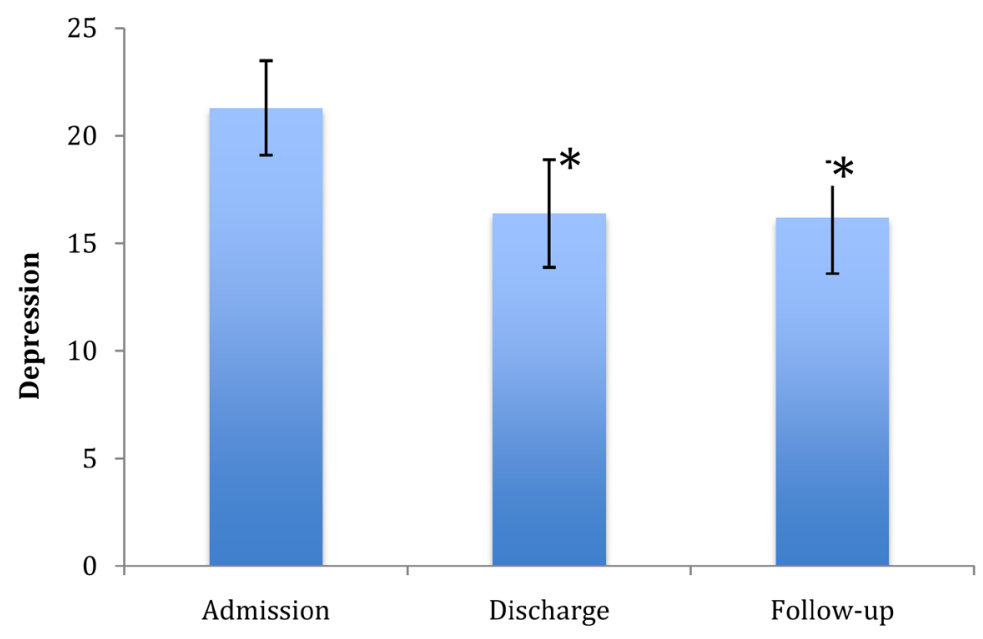

Figure 6. DASS-Depression Subscale (0-42), Discharge, 1-week, Follow-up, 2 -month, ${ }^{\star} \mathrm{p}<0.05$.

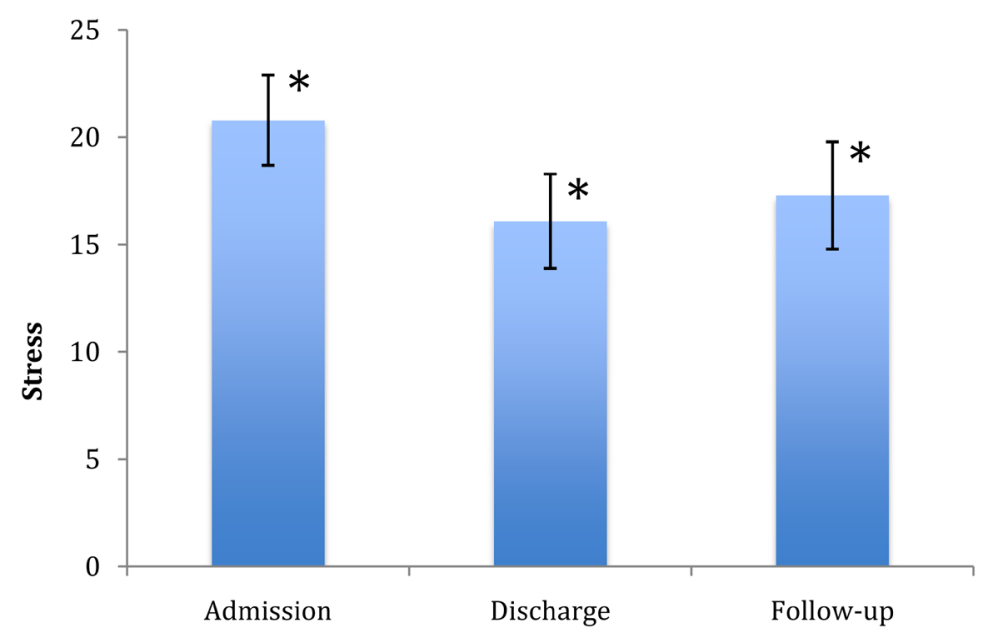

Figure 7. DASS-Stress Subscale (0-42), Discharge, 1-week, Follow-up, 2-month, ${ }^{*} \mathrm{p}<0.05$.

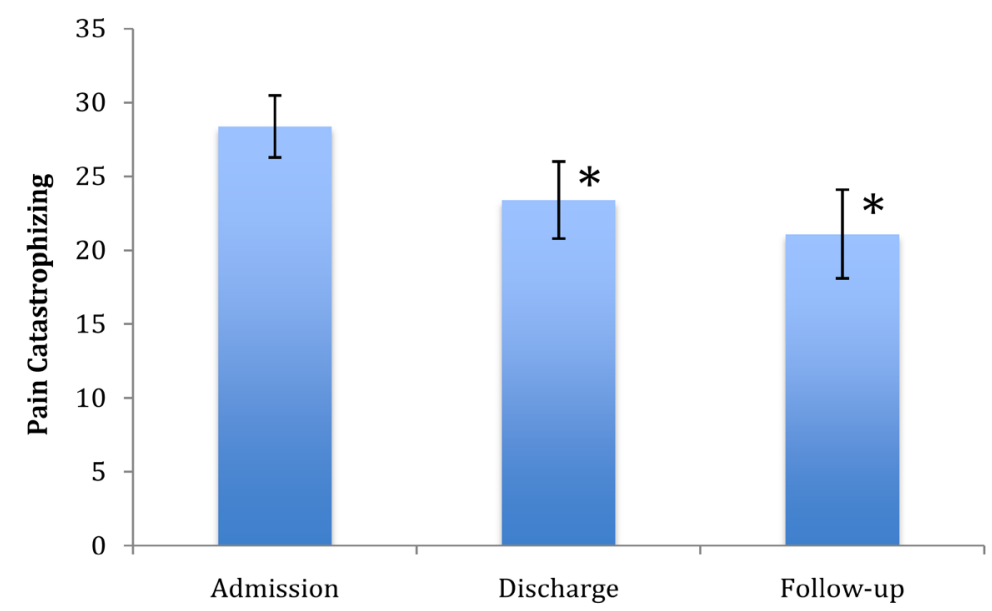

Figure 8. Pain Catastrophizing (PCS) - Total Score (0-52), Discharge, 1-week, Follow-up, 2-month, ${ }^{*} \mathrm{p}<0.05$. 
answering these items. As the Pain Relief item was not used at the two-month follow-up, it was replaced as the determinant of response by the BPI-Pain Severity score [32]. IMMPACT recommends that a moderately important clinically significant reduction in pain is $30 \%$ or more on the BPI-Pain Severity score [33] [34]. Therefore, a 30\% cut-off was used to determine a successful response to the ketamine infusion at 1-week on discharge and at 2-month follow-up.

At 1-week (on discharge), there were 13 responders and 22 non-responders for a response rate of $37 \%$. Females were evenly split across responders $(\mathrm{N}=11)$ and non-responders $(\mathrm{N}=8)$, while males were much less likely to be responders $(\mathrm{N}=2)$ than non-responders $(\mathrm{N}=14)\left(\chi_{1}^{2}=07.67, p=0.006\right)$. On admission there were no differences between responders and non-responders in age, BMI, oMEDD or on any of the psychological measures $\left(t_{33}<1.19, p>0.244\right)$. There was no difference in responder rate for the four pain classifications $\left(\chi_{3}^{2}=0.610\right.$, $p=0.894)$ as shown in Table 3.

At 1-week (on discharge), responders reported lower scores than non-responders on Pain Severity $\left(t_{33}=5.13, p<0.001\right)$, Pain Interference $\left(t_{32}=4.59, p<0.001\right)$ and Stress $\left(t_{33}=2.18, p=0.037\right)$. There were no differences in oMEDD, Depression, Anxiety, PSEQ and PCS $\left(t_{33}<1.97, p>0.058\right)$.

At 2-month follow-up, there were no significant outcome differences among the 25 completers between responders $(\mathrm{N}=8)$ and non-responders $(\mathrm{N}=17)$ on any chronic pain outcome measure $\left(t_{23}<1.58, p>0.128\right)$. However, at 2 -month follow-up, only 3 of the $8(38 \%)$ responders reported a sustained reduction in Pain Severity of $30 \%$ or more, while 1 of the $17(6 \%)$ non-responders reported such a reduction. Therefore, overall treatment response rate at 2 -month follow-up was 4 out of 25 (16\%).

4) Global Perception of Improvement (GPI)

At discharge the GPI items Overall Status and Pain Relief were completed by 26 of the 35 patients. Overall Status was reported to be improved by $81 \%$ of these patients (very much improved $\mathrm{N}=5,19 \%$; much improved $\mathrm{N}=8,31 \%$; and minimally improved $\mathrm{N}=8,31 \%)$. Four patients reported no change (15\%) and one reported being minimally worse $(4 \%)$.

5) Adverse Effects

Table 3. Responders to ketamine infusion by pain classification.

\begin{tabular}{cccc}
\hline & \multicolumn{3}{c}{ Responder } \\
\hline Pain class & Y & N & Total \\
\hline Nociplastic & 4 & 9 & 13 \\
Neuropathic & 4 & 7 & 11 \\
Nociceptive & 2 & 2 & 4 \\
Mixed & 3 & 4 & 7 \\
Total & 13 & 22 & 35 \\
\hline
\end{tabular}


The incidence of adverse effects related to treatment was categorized into central nervous system (CNS) (e.g. neurocognitive disturbance, hallucination, dizziness), gastrointestinal (e.g. nausea, vomiting, abdominal bloating), skin (e.g. redness on insertion site, itchiness, inflammation/infection), and others (e.g. hepatic, urological). A total of 28 patients completed the data of adverse effects at the end of infusion on discharge. The majority of patients experienced CNS-related adverse effects $(n=19)$, followed by gastrointestinal $(n=13)$, skin $(n=11)$ and others $(n=1)$. Some patients described multiple adverse effects on different systems. Only 4 out of 28 patients (14\%) described no adverse effects as shown in Figure 9. Most adverse effects were mild in severity, transient and no treatment was required except reduction in infusion dosage. No patients were severely disturbed by neurocognitive adverse effects.

6) Validity of Measures as Inpatients

Responses to some of the outcome measures on discharge are likely to be related to the limitations imposed by the experience of being an inpatient. For example, the BPI-Pain Interference scale asks patients to report how much pain has interfered during the past week with general activity, mood, walking ability, normal work, relations with other people, sleep and enjoyment of life. Change or the lack of change from admission to discharge should be viewed in this context.

\section{Discussion}

Approximately $20 \%$ of the adult Australian population experience persistent pain, and of these people, one third have high levels of disability [35] [36]. Globally, chronic refractory pain is the leading cause of years lost to disability, and poor physical and mental health [37]. Chronic refractory pain can be defined as persistent pain, which is resistant to conventional medical therapies, or neuropathic, nociceptive and other pain complicated by the development of central

\section{Percentage of Patient-Related Adverse Effects}

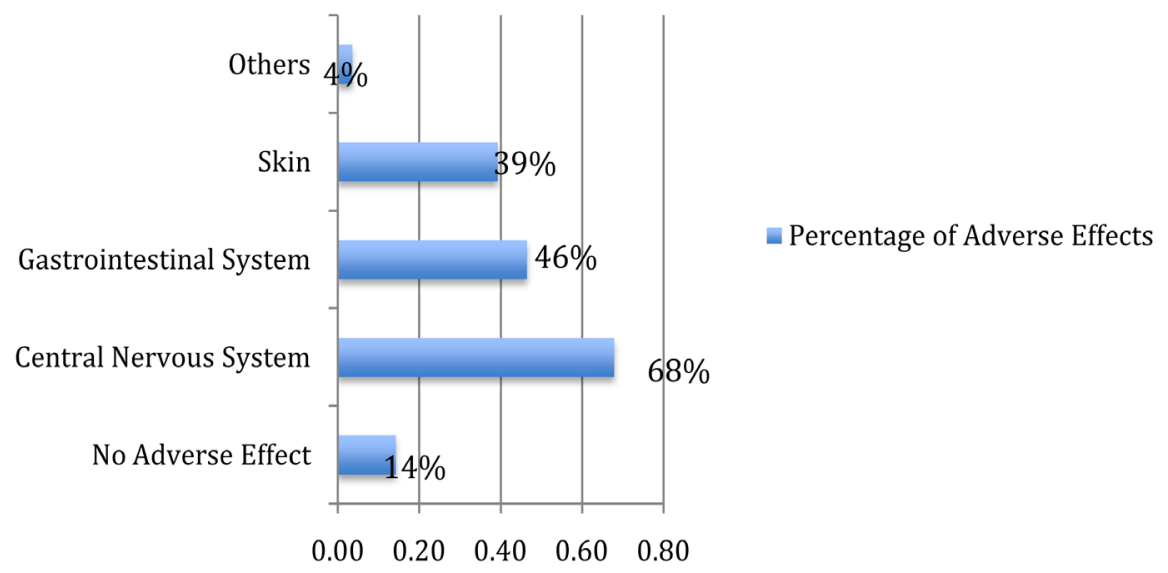

Figure 9. Total 28 patients (100\%), Others-hepatic, renal systems, Skin-catheter skin site reactions, inflammations, Gastrointestinal-nausea, vomiting, abdominal discomfort, Central nervous system-neurocognitive, hallucinations-visual. 
sensitization [38] [39]. They may lead to development of depression [40], anxiety, overuse of opioid analgesics with the risk of dependence and toxicity [41] and increase the risk of suicide [42].

Ketamine as a potent NMDA receptor antagonist has anti-neuropathic, anti-hyperalgesic, anti-depressant and opioid sparing effects [43] [44]. Recently, its metabolite Hydroxynorketamine (HNK) is postulated to produce rapid (within days and weeks) antidepressant and anti-suicidality effects [45] mediated by activation of the AMPA receptor [46]. As part of a multidisciplinary approach, ketamine as an adjuvant pharmacotherapy may be able to modify pain cognitions and coping strategies to improve pain management and quality of life [47]. This may be aided by ketamine's neuromodulatory effect on both the somato-sensory and affective-motivational dimensions of pain by enhancing neural activity in anterior cingulate cortex, orbital frontal cortex, insula and brainstem in healthy volunteers [48].

The pain numerical rating scale effect size of this small study was consistent with other randomized control trials [9] [10] [11] [12] in showing rapid onset of analgesic effect within 1-week ( 6.5 to 5.1 , effect size $-0.6, \mathrm{p}<0.001)$ and sustained up to 2 -month ( 6.5 to 5.9 , effect size $-0.4, \mathrm{p}=0.042$ ). Previous postoperative systematic review demonstrated effect size of short-term analgesic response of -0.59 for ketamine dosage $\leq 0.5 \mathrm{mg} / \mathrm{kg}$ and -0.81 for dosage exceeding 1.0 $\mathrm{mg} / \mathrm{kg}$ [49]. Another systematic review and meta-analysis of randomized controlled trials for chronic pain reported small effect up to 2 weeks after ketamine infusion with significant mean pain difference in pain scores, -1.83 points on 0 10 numerical rating scale [19].

There was a reduction in opioid dose (oMEDD) from mean $199 \mathrm{mg}$ to $122 \mathrm{mg}$ at 1 week $(\mathrm{p}=0.023,36 \%$ reduction) and $93 \mathrm{mg}$ at 2 -month $(\mathrm{p}=0.016,51 \%$ reduction). This is consistent with that reported in another longitudinal study of ketamine infusion followed by long-term ketamine sublingual lozenge therapy [50]. The opioid usage as measured by the oMEDD was reduced by $59 \%$ following inpatient ketamine intravenous infusion for 5 days. The authors found that the use of ketamine lozenges was effective in maintaining the cessation of opioid therapy in $31 \%$ of their patients. Ketamine was found to be safe, and efficacious in facilitating opioid reduction in chronic refractory pain patients.

Interestingly, while there was no improvement in anxiety, there was an additional benefit of sustained improvement in depression at 2-month follow-up ( $\mathrm{p}=$ 0.002), with a rapid onset of effect after 1-week of ketamine infusion. Ketamine could then potentially be utilized as a "circuit breaker" and a bridging therapy to other antidepressant effect and analgesic response. It is notable in our study that there were sustained improvements in pain catastophizing cognitions beyond the direct pharmacological actions of ketamine itself. These psychological effects were unlikely to be related to inpatient hospitalization since they were sustained at 2-month. The effects on psychosocial domains and pain cognition are important in the multidisciplinary management of chronic refractory pain as pain in- 
tensity itself may not be the best measure of efficacy of chronic pain management [51]. Some clinicians opined that nothing is more revealing and therapeutic than a conversation between a patient and a clinician. No quantitative measure of pain severity will ever capture the complexity of the multidimensional nature of chronic pain and patient needs for empathy and yearnings to be heard and respected by an empathetic physician. The inpatient hospitalization as an intervention itself may have provided other contextual effects of hope and expectation of pain relief.

The significant improvements in pain interference and self-efficacy at both 1-week and 2-month should be interpreted cautiously. Patients were not allowed to have full functional autonomy while undergoing continuous ketamine infusion as an inpatient. Short duration of ketamine burst infusions (e.g. 4 hours) in the outpatient setting would be more appropriate to measure changes in pain interference and self-efficacy and less costly for the management of chronic pain than a 5-day inpatient treatment. Nevertheless, there is renewed interest in ketamine infusion given at anaesthetic doses for 5 days under deep sedation in the intensive care unit for treatment of intractable complex regional pain syndrome with high opioid dependence and low quality of life. A phase II open label trial showed a significant reduction in numerical rating scale from baseline in 1 week after infusion ( 8.9 vs. $0.5, \mathrm{p} \leq 0.001)$ and 6 months after infusion (8.9 vs. $2.0, \mathrm{p}<$ 0.001) [52]. Our study was targeted to chronic pain patients with oMEDD of opioid usage between 100 - $300 \mathrm{mg}$ per day who had severely depressed mood and catastrophization. Our subanaesthetic dose inpatient ketamine continuous infusion for 5 days seemed to be effective in the management of severe and prolonged exacerbation of chronic pain without serious adverse side-effects.

Strengths of the current study include the use of a comprehensive set of standardised evaluative parameters to obtain a multidimensional appreciation of each patient's unique bio-psycho-social profile; prospective nature of the study of clinically relevant data outcomes; inclusion of participants with a variety of heterogenous but common refractory chronic pain conditions; and use of a well-defined, commonly used, and safe method of administration of ketamine using a flexible subanesthetic protocol without specific need for cardiac monitoring.

Limitations of the study include the relatively small sample size; incomplete data; variable ketamine dosing (subanaesthetic dose); heterogenous pain phenotypes; and the absence of measures of temporal summation and quantitative sensations. Our study was not placebo-controlled and randomized, hence limiting generalizability. We did not control for unknown confounders (e.g. confounding effect of opioid rotation and reduction, and other non-opioid drug titrations used concurrently with the ketamine infusion, and the inpatient experience itself). Nevertheless, it is a pragmatic and clinically relevant treatment given in a supervised context as part of multidisciplinary pain management. Finally, this study found ketamine to be safe, well tolerated, and very efficacious in 
facilitating opioid reduction (opioid reduction of $36 \%$ at 1 week and $51 \%$ at 2-month) in patients with chronic pain.

We recommend that future research should continue to use validated multidimensional measures, including patient-reported assessments on pain outcomes, determine the longer term sustainability of opioid dose reductions, and the effectiveness of repeated ketamine infusions. As ketamine infusions require several days of inpatient treatment, investigations could explore different treatment delivery modalities such as day-stay outpatient infusions to reduce patient risk and discomfort as well as hospital-related costs and length of hospital stay. Quantitative Sensory Testing (QST) and testing for the contribution of temporal summation as a surrogate measure for wind-up in central sensitization could also be explored as a predictor of response to ketamine infusion.

\section{Conclusion}

In this small study, inpatient ketamine subanaesthetic dose infusion contributed to improvements in all outcome measures, except anxiety, that were evident at 1 -week on discharge and were maintained for those reporting at 2-month follow-up. There were significant improvements in pain severity and pain interference, depression and stress, pain catastrophization and pain self-efficacy. Oral opioid oMEDD reduction was $36 \%$ at 1 -week and $51 \%$ at 2 -month. There were no group differences between responders versus non-responders analysis in psychological outcome and pain classifications. Rates of adverse effects from ketamine infusion were high but these were mostly mild, requiring no specific treatment other than dose adjustment.

\section{Conflicts of Interest}

The authors declare no conflicts of interest regarding the publication of this paper.

\section{References}

[1] Bell, R.F. (2009) Ketamine for Chronic Non-Cancer Pain. Pain, 141, 210-214. https://doi.org/10.1016/j.pain.2008.12.003

[2] Borsook, D. (2009) Ketamine and Chronic Pain-Going the Distance. Pain, 145, 271-272. https://doi.org/10.1016/j.pain.2009.05.021

[3] Berman, R.M., Cappiello, A., Anand, A., et al. (2000) Antidepressant Effects of Ketamine in Depressed Patients. Biological Psychiatry, 47, 351-354. https://doi.org/10.1016/S0006-3223(99)00230-9

[4] Murrough, J.W., Iosifescu, D.V., Chang, L.C., et al. (2013) Antidepressant Efficacy of Ketamine in Treatment-Resistant Major Depression: A Two-Site Randomized Controlled Trial. The American Journal of Psychiatry, 170, 1134-1142. https://doi.org/10.1176/appi.ajp.2013.13030392

[5] Cohen, S., Bhatia, A., Buvanendran, A., Schwenk, E.S., Wasan, A.D., Hurley, R., et al. (2018) Consensus Guidelines on the Use of Intravenous Ketamine Infusions for Chronic Pain from the American Society of Regional Anaesthesia and Pain Medicine, the American Academy of Pain Medicine, and the American Society of An- 
aesthesiologist. Regional Anesthesia \& Pain Medicine, 43, 521-546.

https://doi.org/10.1097/AAP.0000000000000808

[6] Niester, M., Martini, C. and Dahan, A. (2014) Ketamine for Chronic Pain: Risks and Benefits. British Journal of Clinical Pharmacology, 77, 357-367.

https://doi.org/10.1111/bcp.12094

[7] Loftus, R.W., Yeager, M.P., Clark, J.A., et al. (2010) Intraoperative Ketamine Reduces Perioperative Opiate Consumption in Opiate-Dependent Patients with Chronic Back Pain Undergoing Back Surgery. Anesthesiology, 113, 639-646. https://doi.org/10.1097/ALN.0b013e3181e90914

[8] Quinlan, J. (2012) The Use of a Subanesthetic Infusion of Intravenous Ketamine to Allow Withdrawal of Medically Prescribed Opioids in People with Chronic Pain, Opioid Tolerance and Hyperalgesia: Outcome at 6 Months. Pain Medicine, 13, 1524-1525. https://doi.org/10.1111/j.1526-4637.2012.01486.x

[9] Schwartzman, R.J., Alexander, G.M., Grothusen, J.R., et al. (2009) Outpatient Intravenous Ketamine for the Treatment of Complex Regional Pain Syndrome: A Double-Blind Placebo Controlled Study. Pain, 147, 107-115.

https://doi.org/10.1016/j.pain.2009.08.015

[10] Sigtermans, M.J., van Hilyen, J.J., Bauer, M.C.R., et al. (2009) Ketamine Produces Effective and Long-Term Pain Relief in Patients with Complex Regional Pain Syndrome Type 1. Pain, 145, 304-311. https://doi.org/10.1016/j.pain.2009.06.023

[11] Amr, Y.M. (2010) Multi-Day Low Dose Ketamine Infusion as Adjuvant to Oral Gabapentin in Spinal Cord Injury Related Chronic Pain: A Prospective, Randomized, Double Blind Trial. Pain Physician, 13, 245-249.

https://doi.org/10.36076/ppj.2010/13/245

[12] Noppers, I., Niesters, M., Swartjes, M., et al. (2011) Absence of Long-Term Analgesic Effect from a Short-Term S-Ketamine Infusion on Fibromyalgia Pain: A Randomized, Prospective, Double Blind, Active Placebo-Controlled Trial. European Journal of Pain, 15, 942-949. https://doi.org/10.1016/j.ejpain.2011.03.008

[13] Gottrup, H., Bach, F.W., Juhl, G. and Jensen, T.S. (2006) Differential Effect of Ketamine and Lidocaine on Spontaneous and Mechanical Evoked Pain in Patients with Nerve Injury Pain. Anesthesiology, 104, 527-536. https://doi.org/10.1097/00000542-200603000-00021

[14] Kvarnström, A., Karlsten, R., Quiding, H., Emanuelsson, B.M. and Gordh, T. (2003) The Effectiveness of Intravenous Ketamine and Lidocaine on Peripheral Neuropathic Pain. Acta Anaesthesiologica Scandinavica, 47, 868-877. https://doi.org/10.1034/j.1399-6576.2003.00187.x

[15] Eichenberger, U., Neff, F., Sveticic, G., et al. (2008) Chronic Phantom Limb Pain: The Effects of Calcitonin, Ketamine, and Their Combination on Pain and Sensory Thresholds. Anesthesia \& Analgesia, 106, 1265-1273. https://doi.org/10.1213/ane.0b013e3181685014

[16] Eide, P.K., Jrum, E., Stubhaug, A., Bremnes, J. and Breivik, H. (1994) Relief of Post-Herpetic Neuralgia with the N-methyl-D-aspartic Acid Receptor Antagonist Ketamine: A Double-Blind, Cross-Over Comparison with Morphine and Placebo. Pain, 58, 347-354. https://doi.org/10.1016/0304-3959(94)90129-5

[17] Krupitsky, E.M., Burakov, A.M., Dunaevsky, I.V., Romanova, T.N., Slavina, T.Y. and Grinenko, A.Y. (2007) Single versus Repeated Sessions of Ketamine-Assisted Psychotherapy for People with Heroin Dependence. Journal of Psychoactive Drugs, 39, 13-19. https://doi.org/10.1080/02791072.2007.10399860

[18] Kamp, J., Van Velzen, M., Olofsen, E., Boon, M., Dahan, A. and Niesters, M. (2019) 
Pharmacokinetic and Pharmacodynamic Considerations for NMDA-Receptor Antagonist Ketamine in the Treatment of Chronic Neuropathic Pain: An Update of the Most Recent Literature. Expert Opinion on Drug Metabolism \& Toxicology, 15, 1033-1041. https://doi.org/10.1080/17425255.2019.1689958

[19] Orhurhu, V., Orhurhu, M.S., Bhatia, A. and Cohen, S.P. (2019) Ketamine Infusions for Chronic Pain: A Systematic Review and Meta-Analysis of Randomized Controlled Trials. Anesthesia \& Analgesia, 129, 241-254.

https://doi.org/10.1213/ANE.0000000000004185

[20] Michelet, D., Brasher, C., Horlin, A.L., Bellon, M., Julien-Marsollier, F., et al. (2018) Ketamine for Chronic Non-Cancer Pain: A Meta-Analysis and Trial Sequential Analysis of Randomized Controlled Trials. European Journal of Pain, 22, 632-646. https://doi.org/10.1002/ejp.1153

[21] Goldberg, M.E., Torjman, M.C., Schwartzman, R.J., Mager, D.E. and Wainer, I. (2010) Pharmacodynamic Profiles of Ketamine (R-) and S(+) with Five Day Inpatient Infusion for the Treatment of Complex Regional Pain Syndrome. Pain Physician, 13, 379-387. https://doi.org/10.36076/ppj.2010/13/379

[22] Correll, G.E., Maleki, J., Gracely, E.J., Muir, J.J. and Harbut, R.E. (2004) Subanaesthetic Ketamine Infusion Therapy: A Retrospective Analysis of a Novel Therapeutic Approach to Complex Regional Pain Syndrome. Pain Medicine, 5, 263-275. https://doi.org/10.1111/j.1526-4637.2004.04043.x

[23] Yang, Y., Maher, D.P. and Cohn, S.P. (2020) Emerging Concepts on the Use of Ketamine for Chronic Pain. Expert Review Clinical Pharmacology, 13, 135-146. https://doi.org/10.1080/17512433.2020.1717947

[24] Mathew, S.J., Shah, A., Lapidus, K., Clark, C., Jarun, N., Ostermeyer, B. and Murrough, J.W. (2012) Ketamine for Treatment-Resistant Unipolar Depression: Current Evidence. CNS Drugs, 26, 189-204. https://doi.org/10.2165/11599770-000000000-00000

[25] Cusin, C., Ionescu, D.C., Pavone, K.J., Akeju, O., et al. (2017) Ketamine Augmentation for Outpatients with Treatment Resistant Depression: Preliminary Evidence for Two Step Intravenous Dose Escalation. Australian and New Zealand Journal of Psychiatry, 51, 55-64. https://doi.org/10.1177/0004867416631828

[26] Baldwin, M., Boilini, H. and Lamvu, G. (2017) Chronic Pain and Suicide: Is There a Role for Ketamine? Military Medicine, 182, 1746-1748.

https://doi.org/10.7205/MILMED-D-17-00034

[27] Short, B., Fong, J., Galvez, V., Shelker, W. and Loo, C.K. (2018) Side-Effects Associated with Ketamine Use in Depression: A Systematic Review. The Lancet, 5, 65-78. https://doi.org/10.1016/S2215-0366(17)30272-9

[28] Noppers, I.M., Niesters, M., Aarts, L., Bauer, M. and Drewes, A.M. (2011) DrugInduced Liver Injury Following a Repeated Course of Ketamine Treatment for Chronic Pain in CRPS Type 1 Patients: A Report of 3 Cases. Pain, 152, 2173-2178. https://doi.org/10.1016/j.pain.2011.03.026

[29] Bell, R.F. (2012) Ketamine for Chronic Noncancer Pain: Concerns Regarding Toxicity. Current Opinion in Supportive and Palliative Care, 6, 183-187. https://doi.org/10.1097/SPC.0b013e328352812c

[30] Dworkin, Allen, R.R., Bellamy, N., et al. (2003) Core Outcome Domains for Chronic Pain Clinical Trials: IMMPACT Recommendations. Pain, 106, 337-345.

https://doi.org/10.1016/j.pain.2003.08.001

[31] Faculty of Pain Medicine ANZCA (2019) Calculation of oMEDD, Attachment PM01 (Appendix 2). https://www.anzca.edu.au 
[32] Little, R.J. and Rubin, D.B. (2019) Statistical Analysis with Missing Data (Vol. 793). John Wiley \& Sons, Hoboken. https://doi.org/10.1002/9781119482260

[33] Dworkin, R.H., et al. (2008) Interpreting the Clinical Importance of Treatment Outcomes in Chronic Pain Clinical Trials: IMMPACT Recommendations. Pain, 9, 105-121.

[34] Farrar, J.T., Young, J.P., LaMoreaux, L., Werth, J.L. and Poole, R.M. (2001) Clinical Important Changes in Chronic Pain Intensity Measured on an 11-Point Numerical Pain Rating Scale. Pain, 94, 149-158. https://doi.org/10.1016/S0304-3959(01)00349-9

[35] Blyth, F.M., March, L.M., Brnabic, A.J.M., et al. (2001) Chronic Pain in Australia: A Prevalence Study. Pain, 89, 127-134. https://doi.org/10.1016/S0304-3959(00)00355-9

[36] Kerr, S., Fairbrother, G., Crawford, M., et al. (2004) Patient Characteristics and Quality of Life among a Sample of Australian Chronic Pain Clinic Attendees. Internal Medicine Journal, 34, 403-409. https://doi.org/10.1111/j.1444-0903.2004.00627.x

[37] Global Burden of Disease Study 2013 Collaborators (2015) Global, Regional and National Incidence, Prevalence, and Years Lived with Disability for 301 Acute and Chronic Diseases and Injuries in 188 Countries, 1990-2013: A Systematic Review Analysis for the Global Burden of Disease Study 2013. The Lancet, 386, 743-800.

[38] Woolf, C.J. (2007) Central Sensitization. Uncovering the Relation between Pain and Plasticity. Anesthesiology, 106, 864-867. https://doi.org/10.1097/01.anes.0000264769.87038.55

[39] Harte, S.E., Harris, E.R. and Clauw, D.J. (2018) The Neurobiology of Central Sensitization. Journal of Applied Biobehavioral Research, 23, e12137.

https://doi.org/10.1111/jabr.12137

[40] Holmes, A., Christelis, N. and Arnold, C. (2012) Depression and Chronic Pain. The Medical Journal of Australia, 1, 17-20. https://doi.org/10.5694/mjao12.10589

[41] Boyer, E.W. (2012) Management of Opioid Analgesic Overdose. The New England Journal of Medicine, 367, 146-155. https://doi.org/10.1056/NEJMra1202561

[42] Campbell, G., Darke, S., Degenhart, L., Townsend, H., et al. (2020) Prevalence and Characteristics Associated with Chronic Noncancer Pain in Suicide Decedents: A National Study. Suicide and Life-Threatening Behavior, 50, 778-791. https://doi.org/10.1111/sltb.12627

[43] Eldufani, J., Nekoui, A. and Blaise, G. (2018) Non-Anaesthetic Effects of Ketamine: A Review Article. The American Journal of Medicine, 131, 1418-1424. https://doi.org/10.1016/j.amjmed.2018.04.029

[44] Iacobucci, G.J., Visnjevac, O., Pourafkari, L. and Nader, N.D. (2017) Ketamine: An Update of Cellular and Subcellular Mechanisms with Implications for Clinical Practice. Pain Physician, 20, E285-E301. https://doi.org/10.36076/ppj.2017.E301

[45] Cusin, C., Ionescu, D.F., Pavone, K.J., et al. (2017) Ketamine Augmentation for Outpatients with Treatment Resistant Depression: Preliminary Evidence for Two-Step Intravenous Dose Escalation. Australian and New Zealand Journal of Psychiatry, 51, 55-64. https://doi.org/10.1177/0004867416631828

[46] Zanoz, P., Moadddel, R., Morris, P.J., et al. (2016) NMDAR Inhibition-Independent Antidepressant Actions of Ketamine Metabolites. Nature, 533, 481-486. https://doi.org/10.1038/nature17998

[47] Faculty Pain Medicine ANZCA (2016) Proposal for Guideline. Low Dose Ketamine Infusion in the Management of Chronic Non-Cancer Pain. ANZCA Website. 
https://www.anzca.edu.au

[48] Niesters, M., Khalil-Mahani, N., Martini, C., Aarts, L., et al. (2012) Effect of Subanaesthetic Ketamine on Intrinsic Functional Brain Connectivity: A Placebo Controlled Functional Magnetic Resonance Imaging Study in Health Volunteers. Anaesthesiology, 117, 868-877. https://doi.org/10.1097/ALN.0b013e31826a0db3

[49] Laskowski, K., Stirling, A., McKay, W.P. and Lim, H.J. (2011) A Systematic Review of Intravenous Ketamine for Postoperative Analgesia. The Canadian Journal of Anesthesia, 58, 911-923. https://doi.org/10.1007/s12630-011-9560-0

[50] Zekry, O., Gibson, S.B. and Aggarwal, A. (2016) Subanaesthetic, Subcutaneous Ketamine Infusion Therapy in the Treatment of Chronic Non-Malignant Pain. Journal of Pain and Palliative Care Pharmacotherapy, 30, L91-L98. https://doi.org/10.3109/15360288.2016.1161690

[51] Ballantyne, J.C. and Sullivan, M.D. (2015) Intensity of Chronic Pain the Wrong Metrics? The New England Journal of Medicine, 373, 2098-2099. https://doi.org/10.1056/NEJMp1507136

[52] Kiefer, R.T., Rohr, P., Ploppa, A., et al. (2008) Efficacy of Ketamine in Anesthetic Dosage for the Treatment of Refractory Complex Regional Pain Syndrome: An Open Label Phase II Study. Pain Medicine, 9, 1173-201.

https://doi.org/10.1111/j.1526-4637.2007.00402.x 